\title{
Associations among autistic traits, cognitive and affective empathy, and personality in adults with autism spectrum disorder and no intellectual disability or language delay
}

Yukihiko Shirayama ( $\square$ shirayama@rapid.ocn.ne.jp)

Teikyo University Chiba Medical Center https://orcid.org/0000-0002-8911-1684

Kazuki Matsumoto

Teikyo Daigaku Chiba Sogo Iryo Center

Sayo Hamatani

Teikyo Daigaku Chiba Sogo Iryo Center

Katsumasa Muneoka

Teikyo University Chiba Medical Center: Teikyo Daigaku Chiba Sogo Iryo Center

Akihiro Okada

Sapporo Kokusai Daigaku

Koichi Sato

Teikyo University Chiba Medical Center: Teikyo Daigaku Chiba Sogo Iryo Center

Primary research

Keywords: ASD, Adult, IRI, QCAE, NEO

Posted Date: April 30th, 2021

DOI: https://doi.org/10.21203/rs.3.rs-463309/v1

License: (c) (1) This work is licensed under a Creative Commons Attribution 4.0 International License.

Read Full License 


\section{Abstract}

Background: Reported empathy deficits in autism spectrum disorder (ASD) could be attributable to other ASD-related features.

Method: We evaluated 28 adults with ASD and no intellectual disability or language delay and 24 agematched healthy control subjects using the Autism-Spectrum Quotient (AQ), Questionnaire of Cognitive and Affective Empathy (QCAE), Interpersonal Reactivity Index (IRI), and NEO Personality InventoryRevised (NEO-PI-R).

Results: Compared to the controls, ASD participants showed lower scores for perspective taking, online simulation, cognitive empathy, and peripheral responsivity on the QCAE, and lower scores for perspective taking and empathic concern on the IRI. Within the ASD group, the AQ scores showed significant relationships with perspective taking, online simulation and cognitive empathy on the QCAE, and perspective taking on the IRI. Only within the ASD group, significant correlations were revealed between personal distress on the IRI with emotional contagion, proximal responsivity, and affective empathy on the QCAE. The ASD group also showed higher scores for neuroticism and lower scores for extraversion on the NEO-PI-R compared to the controls. However, there were no relationships between AQ scores and NEO factors within the ASD group. There were significant correlations of online simulation and affective empathy on the QCAE with extraversion on the NEO-PI-R only within the ASD group. Multiple regression analysis demonstrated that perspective taking score on the QCAE and extraversion score on the NEO-PI-R were good predictor variables to autistic traits on the AQ.

Conclusions: These findings help our understanding of ASD adults with no intellectual disability or language delay.

\section{Background}

People with autism spectrum disorder (ASD) typically have problems with reciprocal social interaction and communication and show restricted interests. As a result, they can experience challenges that interfere with their activities of daily living. Because of difficulties in reading nonverbal interactive cues and responding typically in conversations, they often have troubles with social perception and competence.

In the Diagnostic and Statistical Manual of Mental Disorders, 5th Edition (DSM-5) [1], Asperger syndrome and high-functioning ASD have been rolled into the single category "ASD", with a note to specify language or intellectual impairment or associated conditions (e.g., genetic or medical diagnosis). Asperger syndrome was once distinguished from other ASD conditions by an association with typical early language development, and individuals with intelligence quotient (IQ) scores within or above the normal average range have been described as "high-functioning", although IQ measures are not a criterion for an autism diagnosis. 
Some researchers have suggested that autism is linked to an innate impairment in the ability to perceive and respond to the affective expressions, leading to profound difficulties in social interaction. Impairments in empathy were reported in ASD individuals with normal IQ [2,3]. Empathy involves cognitive and affective components. Cognitive empathy is defined as the capacity to understand other people's feelings, intentions, and beliefs on an intellectual level, while affective empathy is the emotional response to other people's affective state or feelings [4,5]. Cognitive empathy relies on the ability to assess others' intentions and behaviors what is supposed to partially overlap with "theory of mind". Some researchers have reported atypical theory of mind in adolescents and adults with $\operatorname{ASD}[6,7,8]$. Empathy assessment using the Interpersonal Reactivity Index (IRI) [4] demonstrated adults with ASD and no intellectual disability showed impairments in perspective taking scale $[3,8,9,10,11]$, suggesting potential difficulties in representing another person's psychological perspective.

People with ASD have poor ability for stress coping, leading to psychological trauma, selfish behavior, isolation, and a difficulty in trusting others. Thus, adults with ASD might well have acquired personality bias. Investigators found that adults with what was once called Asperger syndrome showed elevated harm avoidance and low self-directedness and cooperativeness on the Temperament and Character Inventory $(\mathrm{TCl})[12,13,14,15]$. Self-directedness and cooperativeness are addressing maturity of personality from the perspective of self and others. The subscales of cooperativeness include social acceptance, empathy, helpfulness and pure-heartedness. Another personality inventory, the NEO Personality Inventory-Revised (NEO-PI-R) [16] is a five-factor model of personality structures in terms of five traits: neuroticism, extraversion, openness, agreeableness, and conscientiousness. Adults with ASD showed high neuroticism and low extraversion, openness, agreeableness and conscientiousness on the NEO-PI-R $[17,18]$. Although the personality traits of neuroticism and extraversion are associated with negative and positive emotional experiences, respectively [19], the relationships between the personality traits and autistic traits in ASD are not well documented.

Empathy can alter the meaning of life and the behavioral response to others. It is well documented that patients with ASD have deficits in empathy. In clinical situations, patients with ASD have biased personality. However, it is unknown whether the autistic behaviors in ASD are related with empathy deficits and personality bias. Here, we hypothesized that empathy deficits and biased personality are constituent parts of autistic behaviors in ASD. To test this hypothesis, we examine what types of components exist in empathy deficits and biased personality and modulate autistic behaviors in adults with ASD and no intellectual disability or language delay. First, we extracted important components in empathy deficits and biased personality in ASD. Second, we examined the relationships among autistic traits, empathy and personality in each group and compared them. Finally, we quantitatively conducted multiple regression analysis to examine the contribution of empathy and personality to the autistic traits.

\section{Methods}

\section{Participants}


This study included 24 adult participants with ASD, average or above-average IQ, and no language delay and 28 healthy control adults. Inclusion criteria required all participants to be drug-naïve. Participating adults with ASD were recruited from the outpatient clinic of Teikyo University Chiba Medical Center, and all met the DSM-5 criteria for ASD, requiring consensus based on more than 4 months of longitudinal follow-up examination by trained psychiatrists and psychologists. Exclusion criteria were a history of head trauma, seizures or other neurological disorders, intellectual disability, or alcohol and substance use disorders. The adults with ASD had no other psychiatric disorders including depression at enrollment. Healthy control subjects with no past history of psychiatric disorders or drug dependence were recruited within the social environment of the authors.

Participant characteristics are shown in Table 1. Adults with ASD scores significantly higher for autistic traits (Autism-Spectrum Quotient, AQ) [20] compared with healthy controls $(p<0.001)$ (Table 1). Also, adults with ASD showed statistical significance on the Autism Diagnostic Observation Schedule, second edition (ADOS-2) for clinical use [21]. The depressive level on the Beck Depression Inventory score (BDI) [22] was significantly higher for the adults with ASD compared with unaffected controls $(p=0.012)$ (Table 1). Full IQ was significantly different between the two groups $(p=0.016)$ (Table 1$)$, but the IQ of all the subjects were within normal range $(I Q>80)$.

Table 1

The participant demographics.

\begin{tabular}{|llll|}
\hline & $\begin{array}{l}\text { Healthy control } \\
(\mathbf{n}=\mathbf{2 8})\end{array}$ & $\begin{array}{l}\text { ASD } \\
(\mathbf{n}=\mathbf{2 4})\end{array}$ & -values \\
\hline Age, years (range) & $\begin{array}{l}30.4 \pm 6.2 \\
(23-44)\end{array}$ & $\begin{array}{l}27.5 \pm 7.5 \\
(18-44)\end{array}$ & 0.144 \\
\hline Gender (male/female) & $12 / 16$ & $14 / 10$ & 0.163 \\
\hline AQ & $17.3 \pm 6.4$ & $32.7 \pm 6.5$ & $<0.001$ *** \\
\hline ADOS-2 for clinical use & $0.5 \pm 1.7$ & $7.13 \pm 2.7$ & $<0.001$ *** \\
\hline BDI & $5.3 \pm 6.4$ & $10.0 \pm 6.5$ & 0.012 * \\
\hline Full IQ & $106.2 \pm 13.7$ & $97.2 \pm 11.7$ & 0.016 * \\
\hline Verbal IQ & $106.4 \pm 13.1$ & $98.4 \pm 13.4$ & 0.033 * \\
\hline Performance IQ & $104.9 \pm 14.1$ & $96.5 \pm 13.8$ & 0.036 * \\
\hline
\end{tabular}

Data are mean \pm SD. ${ }^{\star} p<0.05,{ }^{\star *} p<0.01,{ }^{\star \star \star} p<0.001$ compared to the healthy controls (Student's t-test). AQ: Autism spectrum quotient. ADOS-2: Autism Diagnostic Observation Schedule, 2nd edition. BDI: Beck depression inventory. IQ: intelligence quotient. 


\section{Ethics}

This research was approved by the ethics committee of Teikyo University School of Medicine (ethical committee approval No.17-105) and performed in accordance with the Declaration of Helsinki. Written informed consent was obtained after the procedures had been fully explained to each participant.

\section{V}

The Autism-Spectrum Quotient (AQ), covering autistic traits [20], is a 50 -item self-administered screening questionnaire to identify the degree to which adults of average intelligence might have autism-related features. This test covers five areas: social skills, attention switching, attention to detail, communication, and imagination. The cutoff for ASD is set at $>32$, which captures $80 \%$ of adults with ASD and average or above-average IQ and no language delay; only $2 \%$ of unaffected adults surpass this cutoff. Another study reported that the $A Q$ has good discriminative validity and screening properties with a threshold score of 26 [23].

Questionnaire of Cognitive and Affective Empathy (QCAE), which consist of 31 items, comprising five subscales: perspective taking, online simulation, emotion contagion, proximal responsivity, and peripheral responsivity, was used to assess level of cognitive and affective empathy [24]. The cognitive empathy subcomponents are perspective taking and online simulation, and the affective empathy subcomponents are emotion contagion, proximal responsivity, and peripheral responsivity. The perspective taking scale reflects placing oneself intuitively in another person's shoes. The online simulation component is a more effortful process of attempting to understand the emotional states of others, whereas the emotion contagion reflects the automaticity of mirroring the emotional states of others. Proximal responsivity is the responsiveness of affective situations in a close social context, and peripheral responsivity is the responsiveness to affective situations that occur in a more detached context.

The Interpersonal Reactivity Index (IRI) was used to assess empathy. The IRI consists of 28 items comprising four subscales: perspective taking, fantasy, empathic concern, and personal distress [4]. The perspective taking scale assesses ability to arrive at a cognitive understanding of what another person thinks or feels. The empathic concern scale reflects the tendency to feel compassion and concern for unfortunate others, and the personal distress scale measures self-oriented feelings of anxiety and discomfort in response to other people's suffering. The fantasy scale assesses a person's ability to selfproject into fictional situations.

Personality was assessed using the NEO Personality Inventory-Revised (NEO-PI-R), which relies on the five-factor model of personality: neuroticism, extraversion, openness, agreeableness, and conscientiousness [16]. It consists of 240 items answered on a five-point Likert scale. The mean and SD for each dimension are 50 and 10, respectively. The neuroticism scale identifies individuals who are prone to psychological distress. The extraversion scale refers to individuals who are sociable, communicative and prone to adventure and simulation. The openness scale identifies individuals who are open to new ideas and are unconventional in the set of values. The agreeableness scale assesses the type of 
interaction individuals prefer from compassionate to tough mindedness. The conscientiousness scale assesses the degree of organization, persistence, control, and motivation in goal-directed behavior.

Autism Diagnostic Observation Schedule, second edition (ADOS-2) for clinical use was done to check the ASD character [21]. Beck Depression Inventory score (BDI) was used for assessing depression features [22]. IQ scores were estimated using the Wechsler Adult Intelligence Scale, 3rd edition (WAIS-III) [25].

\section{Statistical analysis}

We began using multiple analysis of variance (MANOVA) to analyze data from five domains of QCAE and four domains of IRI to check for the simultaneous significant differences between the two groups. Additional covariate analysis was performed using analysis of covariance (ANCOVA), treating Beck and full-scale IQ scores as covariates.

Coefficients of AQ scores with QCAE or IRI scores, and NEO factors were estimated within each group by Pearson coefficients. Effects size and statistical power $(a=0.05)$ were calculated using G-power (3.1). Bonferroni correction for multiple comparisons was used when appropriate (QCAE seven scores and IRI four scores, $p<0.05 / 28=0.0018$ ) (QCAE + IRI eleven scores and NEO five scores, $p<0.05 / 55=0.0009$ ).

Multiple regression analysis was conducted, treating $\mathrm{AQ}$ scores as the dependent variable, and disease (ASD vs control), QCAE five subscales (perspective taking, online simulation, emotion contagion, proximal responsivity, peripheral responsivity), IRI four subscales (perspective taking, empathic concern, personal distress, fantasy), and NEO-PI-R five subscales (neuroticism, extraversion, openness, agreeableness, conscientiousness) as independent variables. Chi-square test was used for categorical variables.

Differences were set as significant at $p<0.05$. Analyses were conducted with SPSS version 20 (IBM).

\section{Results}

\section{Empathy measures}

For the QCAE, MANOVA for the five domains indicated a significant group effect $(F=7.425, p<0.001)$, demonstrating that participants with ASD had significantly lower scores for perspective taking $(p<0.001)$, online simulation $(p<0.001)$ and peripheral responsivity $(p=0.005)$, but not for emotion contagion $(p=$ 0.919 ) or proximal responsivity $(p=0.111)$ (Table 2$)$. After controlling for the full-scale IQ and Beck values by ANCOVA, significant differences remained for perspective taking $(p<0.001)$, online simulation $(p<$ $0.001)$ and peripheral responsivity $(p=0.001)$ (Table 2$)$. When we combined the subcategory data into the two categories on the QCAE, $t$-tests showed that adults with ASD had significantly lower scores for cognitive empathy $(p<0.001)$, but not for affective empathy $(p=0.079)$ (Table 2$)$. After adjustment for full-scale IQ and Beck scales by ANCOVA, the difference in cognitive empathy remained significant $(p<$ $0.001)$, but not in affective empathy $(p=0.067)$ (Table 2$)$.

For the IRI, MANOVA of data for the four domains indicated a significant group effect $(\mathrm{F}=7.829, p<$ $0.001)$, showing that the adults with ASD had significantly lower scores for perspective taking $(p<0.001)$ 
and empathic concern $(p=0.010)$, but not for personal distress $(p=0.147)$ or fantasy $(p=0.067)$ (Table 2). After controlling for full-scale IQ and Beck scores by ANCOVA, significant differences remained only for perspective taking $(p<0.001)$ and empathic concern $(p=0.010)$ (Table 2$)$.

The values of effect size and statistical power were shown in Table 2. 
Table 2

Empathy data on the QCAE and IRI.

\begin{tabular}{|c|c|c|c|c|c|}
\hline & $\begin{array}{l}\text { Healthy } \\
\text { control } \\
(n=28)\end{array}$ & $\begin{array}{l}\text { ASD } \\
(n=24)\end{array}$ & $\begin{array}{l}p \text {-values } \\
\text { (uncorrected) }\end{array}$ & $\begin{array}{l}p \text {-values } \\
\text { with } \\
\text { cofactors }\end{array}$ & $\begin{array}{l}\text { Effect } \\
\text { size } \\
\text { (power) }\end{array}$ \\
\hline QCAE & $35.0 \pm 6.4$ & $24.3 \pm 7.7$ & $<0.001 * \star \star$ & $<0.001 * \star \star *$ & 1.511 \\
\hline Perspective taking & & & & & (0.999) \\
\hline QCAE & $34.1 \pm 5.1$ & $26.5 \pm 7.6$ & 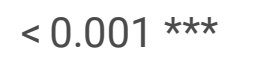 & $<0.001$ *** & 1.174 \\
\hline Online simulation & & & & & $(0.994)$ \\
\hline QCAE & $13.1 \pm 2.8$ & $13.2 \pm 4.3$ & 0.919 & 0.950 & 0.027 \\
\hline Emotion contagion & & & & & $(0.060)$ \\
\hline QCAE & $12.0 \pm 2.6$ & $10.7 \pm 3.3$ & 0.111 & 0.185 & 0.437 \\
\hline Proximal responsivity & & & & & $(0.462)$ \\
\hline QCAE & $14.2 \pm 2.4$ & $11.9 \pm 3.2$ & 0.005 ** & 0.001 ** & 0.813 \\
\hline $\begin{array}{l}\text { Peripheral } \\
\text { responsivity }\end{array}$ & & & & & $(0.892)$ \\
\hline & $69.0 \pm 10.8$ & $\begin{array}{l}50.6 \pm \\
134\end{array}$ & $<0.001 * \star \star$ & $<0.001 * * *$ & \\
\hline Cognitive empathy & & & & & $(0.999)$ \\
\hline QCAE & $39.3 \pm 6.2$ & $35.7 \pm 8.0$ & 0.079 & 0.067 & 0.503 \\
\hline Affective empathy & & & & & $(0.555)$ \\
\hline IRI & $21.2 \pm 2.8$ & $16.6 \pm 3.6$ & $<0.001 * \star \star$ & $<0.001 * * *$ & 1.426 \\
\hline Perspective taking & & & & & $(0.999)$ \\
\hline IRI & $20.7 \pm 3.2$ & $18.7 \pm 2.4$ & 0.010 * & 0.010 * & 0.707 \\
\hline Empathic concern & & & & & $(0.805)$ \\
\hline IRI & $17.5 \pm 4.0$ & $19.3 \pm 4.6$ & 0.147 & 0.247 & 0.417 \\
\hline Personal distress & & & & & $(0.434)$ \\
\hline IRI & $19.8 \pm 3.7$ & $17.7 \pm 4.4$ & 0.067 & 0.059 & 0.516 \\
\hline Fantasy & & & & & $(0.573)$ \\
\hline
\end{tabular}

${ }^{\star} p<0.05,{ }^{* \star} p<0.01,{ }^{* \star \star} p<0.001$. Uncorrected $p$-values are determined by MANOVA followed by $t$-tests. Corrected $p$-values were obtained by a subsequent ANCOVA treating the BDI ad full-scale IQ scores as covariates. The number in the parenthesis is the value of the statistical power $(a=0.05)$. QCAE: Questionnaire of Cognitive and Affective Empathy. IRI: Interpersonal Reactivity Index. 


\section{The correlations of ASD traits with empathy scores on the QCAE and IRI}

Total AQ scores correlated significantly with the perspective taking and cognitive empathy scores on the QCAE, within control group $(r=-0.387, p=0.042 ; r=-0.375, p=0.049)$ and ASD group $(r=-0.510, p=$ $0.011 ; r=-0.579, p=0.003$ ), respectively (Table 3 ). Additionally, total $A Q$ scores correlated significantly with the online simulation scores on the QCAE $(r=-0.499, p=0.013)$ and the perspective taking scores on the IRI $(r=-0.430, p=0.036)$ only among ASD group (Table 3$)$. The peripheral responsivity on the QCAE and the empathic concern on the IRI failed to show significant relationships with autistic traits on the AQ among each group in spite of significance of group comparison (Table 2,3). The values of statistical power showed over 0.80 in half of data with asterisk (Table 3). When Bonferroni corrections were done for these results, the correlation between AQ scores and cognitive empathy on the QCAE within ASD group remains alive $(p<0.05 / 7=0.007)$. The correlation plots for key results (perspective taking, online simulation, and cognitive empathy on the QCAE and perspective taking on the IRI) were shown in Fig. 1. 
Table 3

Relationships between empathy's components and autistic traits.

\begin{tabular}{|c|c|c|c|c|c|}
\hline $\begin{array}{l}\text { Control subjects } \\
(n=28)\end{array}$ & $A Q$ & $\begin{array}{l}\text { IRI } \\
\text { Perspective taking }\end{array}$ & $\begin{array}{l}\text { IRI } \\
\text { Empathic concern }\end{array}$ & $\begin{array}{l}\text { IRI } \\
\text { Personal } \\
\text { distress }\end{array}$ & $\begin{array}{l}\text { IRI } \\
\text { Fantasy }\end{array}$ \\
\hline $\mathrm{AQ}$ & & -0.315 & 0.056 & 0.301 & -0.054 \\
\hline QCAE & -0.387 * & 0.597 ** & 0.136 & -0.186 & 0.113 \\
\hline Perspective taking & $(0.697)$ & $(0.985)$ & & & \\
\hline $\begin{array}{l}\text { QCAE } \\
\text { Online simulation }\end{array}$ & -0.299 & $\begin{array}{l}0.669 * \star * \\
(0.998)\end{array}$ & 0.214 & -0.227 & 0.163 \\
\hline $\begin{array}{l}\text { QCAE } \\
\text { Emotional contagion }\end{array}$ & -0.002 & 0.011 & 0.281 & 0.158 & 0.335 \\
\hline $\begin{array}{l}\text { QCAE } \\
\text { Proximal responsivity }\end{array}$ & -0.068 & -0.064 & $\begin{array}{l}0.395 * \\
(0.715)\end{array}$ & 0.166 & 0.279 \\
\hline $\begin{array}{l}\text { QCAE } \\
\text { Peripheral responsivity }\end{array}$ & -0.361 & 0.010 & $\begin{array}{l}0.443 * \\
(0.816)\end{array}$ & 0.069 & $\begin{array}{l}0.561 * * \\
(0.967)\end{array}$ \\
\hline $\begin{array}{l}\text { QCAE } \\
\text { Cognitive empathy }\end{array}$ & $\begin{array}{l}-0.375 * \\
(0.669)\end{array}$ & $\begin{array}{l}0.670 * * * \\
(0.998)\end{array}$ & 0.182 & -0.215 & 0.148 \\
\hline $\begin{array}{l}\text { QCAE } \\
\text { Affective empathy }\end{array}$ & -0.172 & 0.007 & $\begin{array}{l}0.468 \text { * } \\
(0.860)\end{array}$ & 0.168 & $\begin{array}{l}0.490 * * \\
(0.894)\end{array}$ \\
\hline
\end{tabular}




\begin{tabular}{|c|c|c|c|c|c|}
\hline $\begin{array}{l}\text { ASD patients } \\
(n=24)\end{array}$ & $\mathrm{AQ}$ & $\begin{array}{l}\text { IRI } \\
\text { Perspective taking }\end{array}$ & $\begin{array}{l}\text { IRI } \\
\text { Empathic concern }\end{array}$ & $\begin{array}{l}\text { IRI } \\
\text { Personal } \\
\text { distress }\end{array}$ & $\begin{array}{l}\text { IRI } \\
\text { Fantasy }\end{array}$ \\
\hline $\mathrm{AQ}$ & & $\begin{array}{l}-0.430 * \\
(0.730)\end{array}$ & -0.078 & 0.308 & -0.064 \\
\hline $\begin{array}{l}\text { QCAE } \\
\text { Perspective taking }\end{array}$ & $\begin{array}{l}-0.510 \text { * } \\
(0.878)\end{array}$ & $\begin{array}{l}0.581 \text { ** } \\
(0.959)\end{array}$ & 0.079 & -0.327 & -0.066 \\
\hline $\begin{array}{l}\text { QCAE } \\
\text { Online simulation }\end{array}$ & $\begin{array}{l}-0.499 * \\
(0.871)\end{array}$ & $\begin{array}{l}0.821 * * \star \\
(0.999)\end{array}$ & -0.115 & -0.292 & -0.030 \\
\hline $\begin{array}{l}\text { QCAE } \\
\text { Emotional contagion }\end{array}$ & 0.098 & 0.095 & $\begin{array}{l}0.528 * \star \\
(0.904)\end{array}$ & $\begin{array}{l}0.576 \text { ** } \\
(0.955)\end{array}$ & 0.223 \\
\hline $\begin{array}{l}\text { QCAE } \\
\text { Proximal responsivity }\end{array}$ & 0.010 & 0.290 & 0.294 & $\begin{array}{l}0.555 * \star \\
(0.935)\end{array}$ & 0.074 \\
\hline $\begin{array}{l}\text { QCAE } \\
\text { Peripheral } \\
\text { responsivity }\end{array}$ & -0.085 & 0.007 & -0.028 & -0.170 & $\begin{array}{l}0.541 * * \\
(0.920)\end{array}$ \\
\hline $\begin{array}{l}\text { QCAE } \\
\text { Cognitive empathy }\end{array}$ & $\begin{array}{l}-0.579 \\
\star \star \\
(0.957)\end{array}$ & $\begin{array}{l}0.791 * \star \star \\
(0.999)\end{array}$ & -0.019 & -0.355 & -0.057 \\
\hline $\begin{array}{l}\text { QCAE } \\
\text { Affective empathy }\end{array}$ & 0.022 & 0.174 & 0.394 & $\begin{array}{l}0.471 * \\
(0.813)\end{array}$ & 0.370 \\
\hline
\end{tabular}

${ }^{*} p<0.05,{ }^{\star \star} p<0.01,{ }^{* \star} p<0.001$ in each group. The number in the parenthesis is the value of the statistical power. AQ: Autism-Spectrum Quotient. IRI: Interpersonal Reactivity Index. QCAE: Questionnaire of Cognitive and Affective Empathy.

\section{The relationships among empathy scores on the QCAE and IRI}

The purpose of the correlation analyses between subscales in the QCAE and subscales in the IRI was to examine the difference and relations between the items for empathic traits on the two questionnaires within healthy control and ASD patient groups.

As for empathy scores, we found strong correlations of the perspective taking scores on the IRI with the perspective taking, online simulation and cognitive empathy scores on the QCAE for controls $(r=0.597, p$ 
$=0.001 ; r=0.669, p<0.001 ; r=0.670, p<0.001)$ and for ASD group $(r=0.581, p=0.003 ; r=0.821, p<$ $0.001 ; r=0.791, p<0.001$ ), respectively (Table 3 ). A previous study showed significant correlations between the perspective scale on the IRI and the perspective taking, online simulation and cognitive empathy scores on the QCAE replicated within control subjects [26]. Also we found significant correlations between peripheral responsivity on the QCAE and fantasy scores on the IRI for control group $(r=0.561, p=0.002)$ and for ASD group $(r=0.541, p=0.006)$ (Table 3$)$.

On the contrary, we found different patterns between the two groups. Among control group there existed correlations between the empathic concern scores on the IRI and the proximal responsivity, peripheral responsivity and affective empathy on the QCAE in addition to between fantasy scores on the IRI and affective scores on the QCAE (Table 3), whereas among ASD group there existed correlations between the empathic concern scores on the IRI and emotional contagion scores on the QCAE in addition to between the personal distress scores on the IRI and emotional contagion, proximal responsivity and affective empathy scores on the QCAE (Table 3).

The statistical powers showed over 0.80 in half of data with asterisk (Table 3). When Bonferroni corrections were done for these results of ASD patients, the correlations between online simulation and cognitive empathy on the QCAE and perspective taking on the IRI remain alive $(p<0.05 / 28=0.0014)$.

\section{Personality Scores}

For the NEO-PI-R, MANOVA indicated a significant group effect $(F=8.951, p<0.001)$, demonstrating that compared with control subjects, the adults with ASD had significantly higher scores for neuroticism ( $p<$ $0.001)$ and lower scores for extraversion $(p<0.001)$, agreeableness $(p=0.028)$ and conscientiousness $(p$ $=0.004)$, but no differences in openness $(p=0.271)$ on the NEO-PI-R, (Table 4). After controlling for the full scale IQ and Beck scales by ANCOVA, significant differences remained in neuroticism $(p=0.004)$ and extraversion $(p<0.001)$, but not in agreeableness $(p=0.098)$ or conscientiousness $(p=0.065)$ (Table 4$)$. The values of effect size and statistical power were shown in Table 4. 
Table 4

Personality data on the NEO-PI-R.

\begin{tabular}{|c|c|c|c|c|c|}
\hline & $\begin{array}{l}\text { Healthy } \\
\text { control } \\
(n=28)\end{array}$ & $\begin{array}{l}\text { ASD } \\
\text { subjects } \\
(n=24)\end{array}$ & $\begin{array}{l}\text { p-values } \\
\text { (uncorrected) }\end{array}$ & $\begin{array}{l}p \text {-values } \\
\text { with } \\
\text { cofactors }\end{array}$ & $\begin{array}{l}\text { Effect } \\
\text { size } \\
\text { (power) }\end{array}$ \\
\hline Neuroticism & $55.2 \pm 10.4$ & $67.8 \pm 10.7$ & $<0.001 * \star \star$ & 0.004 ** & $\begin{array}{l}1.194 \\
(0.995)\end{array}$ \\
\hline Extraversion & $49.8 \pm 11.9$ & $34.7 \pm 8.7$ & $<0.001 * \star \star$ & $<0.001 * \star \star$ & $\begin{array}{l}1.448 \\
(0.999)\end{array}$ \\
\hline Openness & $51.9 \pm 7.1$ & $49.4 \pm 9.4$ & 0.271 & 0.338 & $\begin{array}{l}0.300 \\
(0.280)\end{array}$ \\
\hline Agreeableness & $48.1 \pm 11.6$ & $40.6 \pm 12.4$ & 0.028 * & 0.098 & $\begin{array}{l}0.619 \\
(0.708)\end{array}$ \\
\hline Conscientiousness & $45.6 \pm 10.3$ & $36.6 \pm 11.4$ & 0.004 ** & 0.065 & $\begin{array}{l}0.828 \\
(0.901)\end{array}$ \\
\hline
\end{tabular}

${ }^{*} p<0.05,{ }^{*} p<0.01,{ }^{* \star \star} p<0.001$. Uncorrected $p$-values are determined by MANOVA followed by $t$-tests. Corrected $p$ values were done by subsequent ANCOVA, treating BDI ad full-scale IQ scores as covariates. The number in the parenthesis is the value of the statistical power. NEO-PI-R: NEO Personality InventoryRevised.

\section{Correlations Of AQ Scores With Neo Personality Scores}

We found significant correlations between AQ scores and NEO personality scores: for neuroticism among healthy controls $(r=0.404, p=0.033)$ and total participants $(r=0.514, p<0.001)$, but not among ASD group $(r=-0.015, p=0.943$; for extraversion among healthy controls $(r=-0.668, p<0.001)$ and total participants $(r=-0.733, p<0.001)$, but not among ASD group $(r=-0.357, p=0.086)$; for conscientiousness among healthy controls $(r=-0.435, p=0.021)$ and total participants $(r=0.4333, p=0.001)$, but not among ASD group ( $r=-0.010, p=0.964$ (Table 5$)$. The values of statistical power were shown in Table 5. The correlation plots for key results (neuroticism, extraversion and conscientiousness on the NEO-PI-R) were shown in Fig. 2. 
Table 5

Correlations between AQ scores and NEO-PI-R categories.

\begin{tabular}{|lll|}
\hline Healthy controls $(\mathbf{n = 2 8 )}$ & AQ & (power) \\
\hline Neuroticism & 0.404 * & $(0.735)$ \\
\hline Extraversion & -0.668 *** & $(0.998)$ \\
\hline Openness & 0.185 & \\
\hline Agreeableness & 0.118 & \\
\hline Conscientiousness & $-0.435 *$ & $(0.800)$ \\
\hline ASD $(\mathbf{n}=24)$ & AQ & (power) \\
\hline Neuroticism & -0.015 & \\
\hline Extraversion & -0.357 & $(0.567)$ \\
\hline Openness & -0.160 & \\
\hline Agreeableness & 0.013 & \\
\hline Conscientiousness & -0.010 & \\
\hline
\end{tabular}

\begin{tabular}{|lll|}
\hline Total subjects $(\mathbf{n}=\mathbf{5 2})$ & AQ & (power) \\
\hline Neuroticism & $0.514 * * *$ & $(0.995)$ \\
\hline Extraversion & $-0.733 * * *$ & $(1.000)$ \\
\hline Openness & -0.120 & \\
\hline Agreeableness & -0.194 & \\
Conscientiousness & $-0.433 * \star$ & $(0.961)$ \\
\hline
\end{tabular}

${ }^{*} p<0.05,{ }^{*} p<0.01,{ }^{* \star} p<0.001$, coefficient in each group. The number in the parenthesis is the value of the statistical power. AQ: Autism-Spectrum Quotient. NEO-PI-R: NEO Personality Inventory-Revised.

\section{Relationships of personality factors on the NEO-PI-R with empathy scales on the QCAE and IRI scales}

Within each control group and ASD group, we found significant correlations of neuroticism on the NEO-PI$\mathrm{R}$ with emotion contagion on the QCAE ( $\mathrm{r}=0.522, p=0.004 ; \mathrm{r}=0.446, p=0.029$, respectively), with affective empathy on the QCAE ( $r=0.492, p=0.008 ; r=0.481, p=0.017$, respectively), and with fantasy on the IRI ( $r=0.480, p=0.010 ; r=0.447, p=0.029$, respectively) (Table 6). Further, we found correlations of extraversion on the NEO-PI-R with peripheral responsivity on the QCAE $(r=0.499, p=0.007 ; r=0.490, p=$ 
0.015 , respectively), and of openness on the NEO-PI-R with peripheral responsivity on the QCAE $(r=0.531$, $p=0.004 ; r=0.501, p=0.013$, respectively) (Table 6).

Within only ASD group, we found significant correlations between neuroticism on the NEO-PI-R and personal distress on the IRI $(r=0.486, p=0.016)$, extraversion on the NEO-PI-R and online simulation on the QCAE $(r=0.444, p=0.030)$, extraversion on the NEO-PI-R and peripheral responsivity on the QCAE $(r=$ $0.490, p=0.015)$, openness on the NEO-PI-R and online simulation on the QCAE $(r=0.480, p=0.018)$, and conscientiousness on the NEO-PI-R and perspective taking on the IRI $(r=0.511, p=0.011)$ (Table 6).

The statistical powers showed over 0.80 in half of data with asterisk (Table 6). However, when Bonferroni corrections were done for these results, no positive results remain alive $(p<0.05 / 55=0.0009)$. 
Table 6

Correlations between empathy and personality.

\begin{tabular}{|c|c|c|c|c|c|}
\hline $\begin{array}{l}\text { Control } \\
(n=28)\end{array}$ & $\begin{array}{l}\text { NEO } \\
\text { Neuroticism }\end{array}$ & $\begin{array}{l}\text { NEO } \\
\text { Extraversion }\end{array}$ & $\begin{array}{l}\text { NEO } \\
\text { Openness }\end{array}$ & $\begin{array}{l}\text { NEO } \\
\text { Agreeableness }\end{array}$ & $\begin{array}{l}\text { NEO } \\
\text { Conscientiousness }\end{array}$ \\
\hline QCAE & 0.203 & 0.041 & 0.000 & 0.017 & 0.165 \\
\hline \multicolumn{6}{|l|}{$\begin{array}{l}\text { Perspective } \\
\text { taking }\end{array}$} \\
\hline QCAE & 0.095 & 0.188 & 0.228 & 0.133 & 0.342 \\
\hline \multicolumn{6}{|l|}{$\begin{array}{l}\text { Online } \\
\text { simulation }\end{array}$} \\
\hline QCAE & 0.522 ** & 0.101 & 0.370 & 0.142 & -0.247 \\
\hline $\begin{array}{l}\text { Emotion } \\
\text { contagion }\end{array}$ & $(0.934)$ & & & & \\
\hline QCAE & 0.427 * & 0.236 & 0.389 * & 0.221 & 0.058 \\
\hline $\begin{array}{l}\text { Proximal } \\
\text { responsivity }\end{array}$ & $(0.784)$ & & $(0.7020$ & & \\
\hline QCAE & 0.197 & $0.499 * *$ & 0.531 ** & 0.096 & 0.047 \\
\hline $\begin{array}{l}\text { Peripheral } \\
\text { responsivity }\end{array}$ & & $(0.906)$ & $(0.943)$ & & \\
\hline QCAE & 0.165 & 0.114 & 0.110 & 0.075 & 0.258 \\
\hline \multicolumn{6}{|l|}{$\begin{array}{l}\text { Cognitive } \\
\text { empathy }\end{array}$} \\
\hline QCAE & 0.492 ** & 0.341 & $0.540 * *$ & -0.008 & -0.068 \\
\hline $\begin{array}{l}\text { Affective } \\
\text { empathy }\end{array}$ & $(0.897)$ & & $(0.953)$ & & \\
\hline IRI & 0.030 & 0.001 & -0.003 & 0.186 & 0.192 \\
\hline \multicolumn{6}{|l|}{$\begin{array}{l}\text { Perspective } \\
\text { taking }\end{array}$} \\
\hline IRI & 0.387 * & -0.065 & 0.321 & 0.141 & 0.022 \\
\hline $\begin{array}{l}\text { Empathic } \\
\text { concern }\end{array}$ & $(0.697)$ & & & & \\
\hline IRI & 0.262 & -0.320 & 0.169 & 0.292 & -0.472 * \\
\hline $\begin{array}{l}\text { Personal } \\
\text { distress }\end{array}$ & & & & & $(0.867)$ \\
\hline
\end{tabular}




\begin{tabular}{|llllll|}
\hline Control & NEO & NEO & NEO & NEO & NEO \\
$(\mathbf{n = 2 8 )}$ & Neuroticism & Extraversion & Openness & Agreeableness & Conscientiousness \\
\hline IRI & $0.480 * *$ & 0.168 & 0.343 & 0.015 & -0.191 \\
Fantasy & $(0.879)$ & & & & \\
\hline
\end{tabular}




\begin{tabular}{|c|c|c|c|c|c|}
\hline $\begin{array}{l}\text { ASD patients } \\
(n=24)\end{array}$ & $\begin{array}{l}\text { NEO } \\
\text { Neuroticism }\end{array}$ & $\begin{array}{l}\text { NEO } \\
\text { Extraversion }\end{array}$ & $\begin{array}{l}\text { NEO } \\
\text { Openness }\end{array}$ & $\begin{array}{l}\text { NEO } \\
\text { Agreeableness }\end{array}$ & $\begin{array}{l}\text { NEO } \\
\text { Conscientiousness }\end{array}$ \\
\hline $\begin{array}{l}\text { QCAE } \\
\text { Perspective } \\
\text { taking }\end{array}$ & -0.081 & -0.097 & 0.209 & 0.082 & 0.233 \\
\hline $\begin{array}{l}\text { QCAE } \\
\text { Online } \\
\text { simulation }\end{array}$ & -0.159 & $\begin{array}{l}0.444 \text { * } \\
(0.760)\end{array}$ & $\begin{array}{l}0.480 * \\
(0.829)\end{array}$ & 0.087 & 0.354 \\
\hline $\begin{array}{l}\text { QCAE } \\
\text { Emotion } \\
\text { contagion }\end{array}$ & $\begin{array}{l}0.446 \text { * } \\
(0.764)\end{array}$ & 0.185 & -0.198 & 0.142 & -0.232 \\
\hline $\begin{array}{l}\text { QCAE } \\
\text { Proximal } \\
\text { responsivity }\end{array}$ & 0.327 & 0.324 & 0.074 & 0.229 & 0.200 \\
\hline $\begin{array}{l}\text { QCAE } \\
\text { Peripheral } \\
\text { responsivity }\end{array}$ & 0.262 & $\begin{array}{l}0.490 * \\
(0.846)\end{array}$ & $\begin{array}{l}0.501 \text { * } \\
(0.864)\end{array}$ & -0.403 & -0.268 \\
\hline $\begin{array}{l}\text { QCAE } \\
\text { Cognitive } \\
\text { empathy }\end{array}$ & -0.127 & 0.194 & 0.388 & 0.090 & 0.330 \\
\hline $\begin{array}{l}\text { QCAE } \\
\text { Affective } \\
\text { empathy }\end{array}$ & $\begin{array}{l}0.481 \text { * } \\
(0.831)\end{array}$ & $\begin{array}{l}0.432 * \\
(0.735)\end{array}$ & 0.127 & 0.008 & -0.151 \\
\hline $\begin{array}{l}\text { IRI } \\
\text { Perspective } \\
\text { taking }\end{array}$ & -0.349 & 0.156 & 0.388 & 0.185 & $\begin{array}{l}0.511 * \\
(0.880)\end{array}$ \\
\hline $\begin{array}{l}\text { IRI } \\
\text { Empathic } \\
\text { concern }\end{array}$ & 0.328 & 0.299 & -0.144 & 0.234 & -0.252 \\
\hline $\begin{array}{l}\text { IRI } \\
\text { Personal } \\
\text { distress }\end{array}$ & $\begin{array}{l}0.486 \text { * } \\
(0.839)\end{array}$ & -0.118 & 0.216 & 0.328 & -0.245 \\
\hline $\begin{array}{l}\text { IRI } \\
\text { Fantasy }\end{array}$ & $\begin{array}{l}0.447 * \\
(0.766)\end{array}$ & 0.248 & 0.159 & -0.378 & -0.253 \\
\hline
\end{tabular}


${ }^{\star} p<0.05,{ }^{*} p<0.01$, coefficient in all subjects. The number in the parenthesis is the value of the statistical power. IRI: Interpersonal Reactivity Index. NEO-PI-R: NEO Personality Inventory-Revised. QCAE: Questionnaire of Cognitive and Affective Empathy.

\section{Contributory factors of empathy and personality to autistic traits by multiple regression analysis}

Multiple regression analysis showed goodness-of-fit statistics $\left(R=0.915\right.$, adjusted $R^{2}=0.769, F(15,36)=$ $12.304, p<0.001)$. Results indicated that two factors, perspective taking on the QCAE and extraversion on the NEO-PI-R, were good predictor variables to autistic traits on the AQ scores $(p<0.005 ; p<0.001$, respectively) (Table 7$)$. 
Table 7

Contributory factors to $\mathrm{AQ}$ scores by multiple regression analysis.

\begin{tabular}{|c|c|c|c|c|}
\hline & $\begin{array}{l}\text { Unstandardized } \\
\text { coefficients B }\end{array}$ & $\begin{array}{l}\text { Standardized } \\
\text { coefficients Beta }\end{array}$ & $t$ values & $p$-values \\
\hline (Constant) & $43.167(9.413)$ & & 4.586 & $0.000 * \star *$ \\
\hline Disease & $-4.005(2.401)$ & -.201 & -1.668 & 0.104 \\
\hline $\begin{array}{l}\text { QCAE } \\
\text { Perspective taking }\end{array}$ & $-.422(.140)$ & -.372 & -3.008 & 0.005 ** \\
\hline $\begin{array}{l}\text { QCAE } \\
\text { Online simulation }\end{array}$ & $.011(.207)$ & .008 & 0.052 & 0.959 \\
\hline $\begin{array}{l}\text { QCAE } \\
\text { Emotion contagion }\end{array}$ & .181 (.328) & .064 & 0.551 & 0.558 \\
\hline $\begin{array}{l}\text { QCAE } \\
\text { Proximal responsivity }\end{array}$ & $.076(.426)$ & .023 & 0.180 & 0.858 \\
\hline $\begin{array}{l}\text { QCAE } \\
\text { Peripheral responsivity }\end{array}$ & $-.169(.406)$ & -.051 & -0.417 & 0.679 \\
\hline $\begin{array}{l}\text { IRI } \\
\text { Perspective taking }\end{array}$ & $-.238(.375)$ & -.093 & -0.635 & 0.529 \\
\hline $\begin{array}{l}\text { IRI } \\
\text { Empathic concern }\end{array}$ & $-.010(.312)$ & -.003 & -0.031 & 0.975 \\
\hline $\begin{array}{l}\text { IRI } \\
\text { Personal distress }\end{array}$ & $-.069(.234)$ & -.030 & -0.296 & 0.769 \\
\hline $\begin{array}{l}\text { IRI } \\
\text { Fantasy }\end{array}$ & $-.017(.236)$ & -.007 & -0.072 & 0.943 \\
\hline $\begin{array}{l}\text { NEO } \\
\text { Neuroticism }\end{array}$ & $.077(.099)$ & .093 & 0.772 & 0.445 \\
\hline $\begin{array}{l}\text { NEO } \\
\text { Extraversion }\end{array}$ & $-.374(.086)$ & -.483 & -4.345 & $0.000 * * *$ \\
\hline $\begin{array}{l}\text { NEO } \\
\text { Openness }\end{array}$ & $.196(.110)$ & .162 & 1.789 & 0.082 \\
\hline
\end{tabular}




\begin{tabular}{|lllll|}
\hline & $\begin{array}{l}\text { Unstandardized } \\
\text { coefficients B }\end{array}$ & $\begin{array}{l}\text { Standardized } \\
\text { coefficients Beta }\end{array}$ & t values & $p$-values \\
\hline NEO & $.004(.070)$ & .005 & 0.053 & 0.958 \\
Agreeableness & & & & \\
\hline NEO & $.055(.090)$ & .064 & 0.613 & 0.544 \\
Conscientiousness & & & & \\
\hline
\end{tabular}

${ }^{* \star} p<0.01,{ }^{* \star} p<0.001$ by multiple regression analysis in all subjects.

B: multiple correlation coefficients. The number in the parenthesis is standard errors.

IRI: Interpersonal Reactivity Index. NEO-PI-R: NEO Personality Inventory-Revised. QCAE: Questionnaire of Cognitive and Affective Empathy.

\section{Discussion}

The first finding of the present study is that the adults with ASD and no intellectual disability or language delay showed significantly lower scales for cognitive empathy, but not for affective empathy on the QCAE compared to control subjects (Table 2). In subcategories of cognitive empathy, ASD subjects showed significantly lower scales for perspective taking and online simulation on the QCAE, and for perspective taking on the IRI compared to control subjects (Table 2). In subcategories of affective empathy, ASD subjects showed lower scores for peripheral responsivity on the QCAE and empathic concern on the IRI than control subjects (Table 2). Among these subscales, perspective taking and cognitive empathy on the QCAE demonstrated significant correlations with total AQ scores within each control group and ASD group (Table 3). Furthermore, online simulation on the QCAE and perspective taking on the IRI showed significant correlations with AQ scores only within ASD group (Table 3). The correlation plots for key results command visible comparison between the left control group and right ASD group (Fig. 1). Taken together, it is likely that the cognitive empathy scales as above are related with ASD traits. These findings suggest that autism is profoundly related to deficits in cognitive empathy, especially perspective-taking ability. In support, previous studies of empathy in ASD suggested that in adults with diagnoses such as Asperger syndrome, there were impairments on the perspective taking scale and deficits trends in the fantasy and empathic concern scales on the IRI $[3,8,9,10,11]$.

Cognitive empathy is defined as the ability to construct a working model of the emotional states of others, whereas affective empathy is defined as the ability to be sensitive to and vicariously experience the feelings of others. Furthermore, cognitive empathy has been associated with the dorsomedial prefrontal cortex and midcingulate cortex, whereas affective empathy is linked to activity of the insula $[27,28]$. It is likely that cognitive and affective empathy are distinct categories. Additionally, ASD group 
showed significant alterations in the peripheral responsivity on the QCAE and the empathic concern on the IRI, but these scores did not show any significant correlations with $A Q$ scores within each group (Table 2, Table 3). ASD group failed to show changes in personal distress on the IRI (Table 2), whereas previous studies showed high scores for personal distress on the IRI in the Asperger syndrome and highfunctioning ASD subjects, $[3,8,10,11]$, but one study with no impairments [9]. It might be that deficits in affective empathy in individuals with ASD are difficult to check on the IRI or QCAE. Future study will be needed to elucidate this issue.

The second finding is that there existed contrasting patterns between the two group; significant correlations were seen between the empathic concern on the IRI and the proximal responsivity, peripheral responsivity and affective empathy on the QCAE among control group, whereas a significant correlation was found between the empathic concern on the IRI and emotional contagion on the QCAE among ASD group (Table 3). Here it is natural that there exist significant associations between the affective empathyrelated subscales on the QCAE and IRI. Further, there existed correlations between the personal distress on the IRI and the emotional contagion, proximal responsivity and affective empathy scores on the QCAE only among ASD group (Table 3). These subscales are involved in affective empathy, indicating the important roles of affective empathy. It looks like a kind of shift from the empathic concern to the personal distress because of reductions in scores for empathic concern and increases in scores for personal distress on the IRI in ASD subjects.

The pathway of affective empathy was divided into either empathic concern or personal distress from a view of responding. The tendency to feel compassion and concern for unfortunate others in empathic concern is in the opposite direction to the self-oriented feeling of anxiety and discomfort in response to other people's suffering in personal distress on the IRI. It is supposed that although ASD patients can catch others' painful feeling, they are occupied by self-oriented feeling of distress (personal distress), making them difficult to have empathic concern to other peoples feeling (empathic concern) in affective empathy. This trade-off could be easily brought by the cognitive empathy deficits in case of ASD $[3,8]$. The group differences in peripheral responsivity on the QCAE and empathic concern on the IRI (Table 2) could support the importance of the correlations between peripheral responsivity on the QCAE and fantasy on the IRI and between empathic concern on the IRI and emotional contagion on the QCAE among ASD patients (Table 3). Empathy has two directions to either voluntary behavior intended to benefit another or moral reasoning and social competence [29]. Helping behavior has two alternative motivations, selfless empathic concern in altruism and egoistic personal distress [30]. In another study, perspective taking in empathy needs self-awareness, mental flexibility and emotional regulation, and disturbed self-control process might induce personal distress [31]. Future study about affective empathy will be needed.

The third finding is that the adults with ASD and no intellectual disability or language delay had significantly higher scores for neuroticism and lower scores for extraversion on the NEO-PI-R than control subjects after controlling for the full IQ and Beck scores by ANCOVA (Table 4). AQ scores showed significant relationships with neuroticism, extraversion and conscientiousness on the NEO-PI-R within 
control group and the combined total subjects but not ASD group (Table 5). The correlation plots for key results command visible comparison between the left control group and right ASD group (Fig. 2). It looks that there exists a trend for characteristics of ASD traits when seen from a point of healthy typical developing control. It might be due to the ceiling effects of NEO-PI-R on ASD subjects. In support of this, previous studies using a sample of typically-developing subjects, the five factor model of personality (FFM) accounted for $37 \%$ of AQ scores [32], and the NEO-PI-R predicted $24 \%$ of the variability in AQ scores [33]. However, in other studies, the AQ scores were correlated with extraversion scale on the Eysenck Personality Questionnaire in the control adults and Asperger's syndrome group [34], and all the scales on the FFM correlated with autism symptom severity on the Ritvo Autism/Asperger's Diagnostic Scale Revised [35]. It was unknown whether personality bias on the NEO-PI-R could come from ASD traits on the $A Q$.

The fourth finding is that neuroticism on the NEO-PI-R showed significant relationships with the emotion contagion and affective empathy on the QCAE and the fantasy on the IRI within respective two groups, and extraversion and openness on the NEO-PI-R were significantly associated with the peripheral responsivity on the QCAE within each group (Table 6). Higher levels of neuroticism are associated with threat sensitivity and self-generated thought [36]. Further, within only ASD group, neuroticism on the NEO$\mathrm{PI}-\mathrm{R}$ showed a significant relationship with personal distress on the IRI, and extraversion on the NEO-PI-R showed significant relationships with online simulation and affective empathy on the QCAE (Table 6). These indicated that there exist some relationships between personality components and empathy components. Further studies are required to address these results.

The final finding is that quantitative data analysis using multiple regression analysis showed that two scores, perspective taking on the QCAE and extraversion on the NEO-PI-R, were good predictor variables to autistic traits on the AQ scores (Table 7). It is of note that the two factors, perspective taking on the QCAE in empathy and extraversion on the NEO-PI-R in personality, weight on autistic traits on the AQ rather than disease (ASD vs control). Although ASD patients and healthy controls are different from a medical point of view, the above two factors in empathy and personality field could be significantly located in the pathophysiology of autistic traits in ASD.

\section{Limitations}

This study has some limitations. First, sample sizes are small. Second, participants of two groups showed small differences in IQ between adults with ASD subjects and healthy controls in spite of recruiting participants with normal intelligence (full-scale IQ > 80). Third, ASD group showed depressive state despite that they were not suffering from depression.

\section{Conclusions}

ASD participants with normal IQ and no language delays showed cognitive empathy deficits rather than affective empathy deficits, including the perspective taking, online simulation and peripheral responsivity on the QCAE and the perspective taking and empathic concern on the IRI, compared to healthy controls. 
These three scales were significantly related with autistic traits on the AQ scores. ASD subjects showed higher scores for neuroticism and lower scores for extraversion on the NEO-PI-R compared to healthy controls. However, these biased personality scales did not show any relationship with alterations in AQ scores in ASD subjects. Multiple regression analysis demonstrated that perspective taking score on the QCAE and extraversion score on the NEO-PI-R were good predictor variables to autistic traits on the AQ scores. These results potentially help to explain what might underlie the empathy deficits and personality bias in people with ASD.

\section{Abbreviations}

ADOS-2: The autism diagnostic interview-revised; ANCOVA: analysis of covariance; ASD: Autism spectrum disorder; AQ: Autism-spectrum Quotient; BDI: Beck Depression Inventory; IQ: Intelligence quotient; IRI: Interpersonal Reactivity Index; MANOVA: multiple analysis of variance; NEO-PI-R: NEO Personality Inventory-Revised; QCAE: Questionnaire of Cognitive and Affective Empathy; WAIS-III: Wechsler Adult Intelligence Scale, 3rd edition.

\section{Declarations}

\section{Acknowledgements}

Not applicable

\section{Author Contributions}

The study was designed by YS and AO. Data collection was carried out by YS, KM and KS. Data analysis was carried out by KM and SH. Interpretation of data was done by OA. Writing of the paper was done by YS. All authors read and approved the final manuscript.

\section{Funding}

No funding source.

\section{Availability of data and materials}

The datasets are available from the corresponding author on reasonable request.

\section{Ethics approval and consent to participate}

This research was approved by the ethics committee of Teikyo University School of Medicine. Written informed consent was obtained after the procedures had been fully explained to each participant.

\section{Consent for publication}

Not applicable 


\section{Competing interests}

The authors declare that they have no competing interests.

\section{References}

1. American Psychiatric Association Diagnostic and Statistical Manual of Mental Disorders, fifth ed. American Psychiatric Publishing, Washington DC; 2013.

2. Baron-Cohen $S$, Wheelwright $S$. The empathy quotient: an investigation of adults with Asperger syndrome of high functioning autism, and normal sex differences. J Autism Dev Disord 2004; 34(2): 163-75.

3. Lombardo MV, Barnes JL, Wheelwright SJ, Baron-Cohen S. Self-referential cognition and empathy in autism. PloS One 2007; 2 (9): e883.

4. Davis MH. Measuring individual differences in empathy: evidence for a multidimensional approach. J Pers Social Psychol 1983; 44: 113-26.

5. Singer T. The neuronal basis and outogeny of empathy and mind reading: review of literature and implications for future research. Neurosci Biobehav Rev 2006; 30: 855-63.

6. Blackshaw AJ, Kinderman P, Hare DJ, Hatton C. Theory of mind, causal attribution and paranoia in Asperger syndrome. Autism 2001; 5(2): 147-63.

7. Jones CG, Simonoff E, Baird G, Pickles A, Marsden AJS, Tregay J, et al. The association between theory of mind, executive function, and the symptoms of autism spectrum disorder. Autism Res 2018; 11(1): 95-109.

8. Rogers K, Dziobek I, Hassenstab J, Wolf OT, Convit A. Who cares? Revising empathy in Asperger syndrome. J Autism Dev Disord 2007; 38: 709-15.

9. Minio-Paluello I, Baron-Cohen S, Avenanti A, Walsh V, Aglioti SM. Absence of embodied empathy during pain observation in Asperger syndrome. Biol Psychiatry 2009; 65: 55-62.

10. Ziermans T, de Bruijn Y, Dijkhuis R, Staal W, Swaab H. Impairments in cognitive empathy and alexithymia occur independently of executive functioning in college students with autism. Autism 2019; 23(6): 1519-30.

11. De Coster L, Wiersema JR, Deschrijver E, Brass M. The effects of being imitated on empathy for pain in adults with high-functioning autism: disturbed self-other distinction leads to altered empathic responding. Autism 2018; 22: 712-727.

12. Soderstrom H, Rastam M, Gillberg C. Temperature and character in adults with Asperger syndrome. Autism 2002; 6(3): 287-97.

13. Anckarsäter H, Stahlberg O, Larson T, Hakansson C, Jutblad SB, Niklasson L, et al. The impact of ADHD and autism spectrum disorders on temperament, character, and personality development. Am J Psychiatry 2006; 163(7): 1239-44. 
14. Sizoo BB, van der Gaag RJ, van der Brink W. Temperament and character as endophenotype in adults with autism spectrum disorders or attention deficit/hyperactivity disorder. Autism 2015; 19(4): 400-8.

15. Helles A, Wallinius M, Gillberg C, Gillberg C, Billstedt E. Asperger syndrome in childhood - personality dimensions in adult life: temperament, character and outcome trajectories. $\mathrm{Br} \mathrm{J}$ Psychiatry Open 2016; 2: 210-16.

16. Costa PT, McCrae RR. Stability and change in personality assessment: the revised NEO Personality Inventory in the year 2000. J Pers Assess 1997; 68: 86-94.

17. Schriber RA, Robins RW, Solomon M. Personality and self-insight in individuals with autism spectrum disorder. J Pers Soc Psychol 2014; 106(1): 112-30.

18. Strunz S, Westphal L, Ritter K, Heuser I, Dziobek I, Roepke S. Personality pathology of adults with autism spectrum disorder without accompanying intellectual impairment in comparison to adults with personality disorders. J Autism Dev Disord 2015; 45: 4026-38.

19. McCrae RR, Costa PT. Personality in adulthood. A five-factor theory perspective. New York. Guilford Press; 2003.

20. Baron-Cohen S, Wheelwright S, Skinner R, Martin J, Clubley E. The autism-spectrum quotinent (AQ): evidence from Asperger syndrome / high-functioning autism, males and females, scientists and mathematicians. J Autism Dev Disord 2001; 31: 5-17.

21. Lord C, Risi S, Lambrecht L, Cook EH, Levenhal BL, DiLavore PC, et al. The autism diagnostic schedule-genetic: a standard measures of social and communication deficits associated with the spectrum of autism. J Autism Dev Disord 2000; 30: 205-223.

22. Beck AT, Ward CH, Mendelson M, Mock J, Erbaugh JK. An inventory for measuring depression. Arch Gen Psychiatry 1961; 4: 561-71.

23. Woodbury-Smith MR, Robinson J, Wheelwright S, Baron-Cohen S. Screening adults for Asperger syndrome using the AQ: a preliminary study of its diagnostic validity in clinical practice. J Autism Dev Disord 2005; 35: 331-5.

24. Reniers RLEP, Corcoran R, Drake R, Shryane NM, Völlm A. The QCAE: a questionnaire of cognitive and affective empathy. J Pers Assess 2011; 93: 84-95.

25. Wechsler D. WAIS-III, Wechsler Adult Intelligent Scale, third edition. Technical Manual, Psychological Corporation; 2002.

26. Michaels TM, Horan WP, Ginger EJ, Martinovich Z, Pinkham AE, Smith MJ. Cognitive empathy contributes to poor social functioning in schizophrenia: evidence from a new self-report measure of cognitive and affective empathy. Psychiatry Res 2014; 220: 803-810.

27. Eres R, Decety J, Louis WR, Molenberghs P. Individual differences in local grey matter density are associated with differences in affective and cognitive empathy. Neuroimage 2015; 117: 305-10.

28. Fan Y, Duncan NW, de Greck M, Northoff G. Is there a core neural network in empathy? An fMRI based quantitative meta-analysis. Neurosci Biobehav Rev 2011; 35: 903-11. 
29. Eisenberg N, Miller PA. The relation of empathy to prosocial and related behaviors. Psychol Bull 1987; 101(1): 91-119.

30. Batson CD, Fultz J, Schoenrade PA. Distress and empathy: two qualitatively distinct vicarious emotions with different motivational consequences. J Pers 1987; 55(1): 19-39.

31. Decety J, Jackson PL. The functional architecture of human empathy. Behav Cogn Neurosci Rev 2004; 3(2): 71-100.

32. Austin EJ. Personality correlates of the broader autism phenotype as assessed by the autism spectrum quotient (AQ). Pers Indiv Differ 2005; 38: 451-60.

33. Wakabayashi A, Baron-Cohen S, Wheelwright $S$. Are autistic traits an independent personality dimension? A study of the autism spectrum quotient (AQ) and the NEO-PI-R. Pers Indiv Differ 2006; 41: 873-83.

34. Kanai C, Iwanami A, Ota H, Yamasue H, Matsushima E, Yokoi H, et al. Clinical characteristics of adults with Asperger's syndrome assessed with self-report questionnaires. Res Autism Spec Disord 2011; 5: 185-90.

35. Schwarzman BC, Wood JJ, Kapp SK. Can the five factor model of personality account for the variability of autism symptom expression? Multivariate approaches to behavioral phenotyping in adult autism spectrum disorder. J Autism Dev Disord 2016; 46: 253-72.

36. Perkins AM, Arnone D, Smallwood J, Mobbs D. Thinking too much: self-generated thought as the engine of neuroticism. Trends Cogn Sci 2015;19 (9): 492-498.

\section{Figures}




\section{Control}

ASD
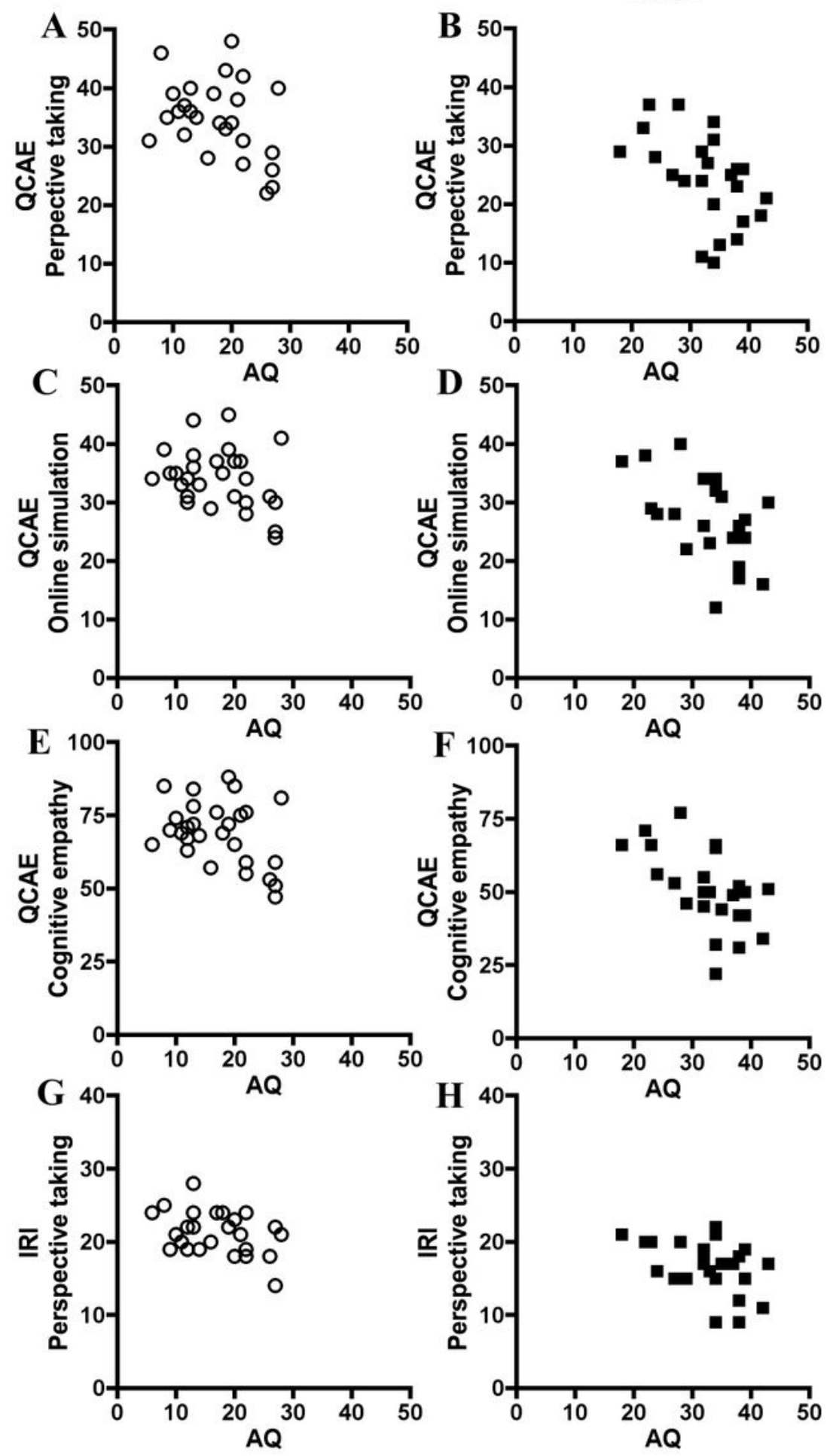

Figure 1

The correlation plots for the association between autistic traits and empathic traits $A, B$ : The correlations between autistic traits on the AQ and perspective taking on the QCAE in the control and ASD subjects. C, $D$ : The correlations between autistic traits on the AQ and online simulation on the QCAE in the control and ASD subjects. E, F: The correlations between autistic traits on the AQ and cognitive empathy on the QCAE 
Control
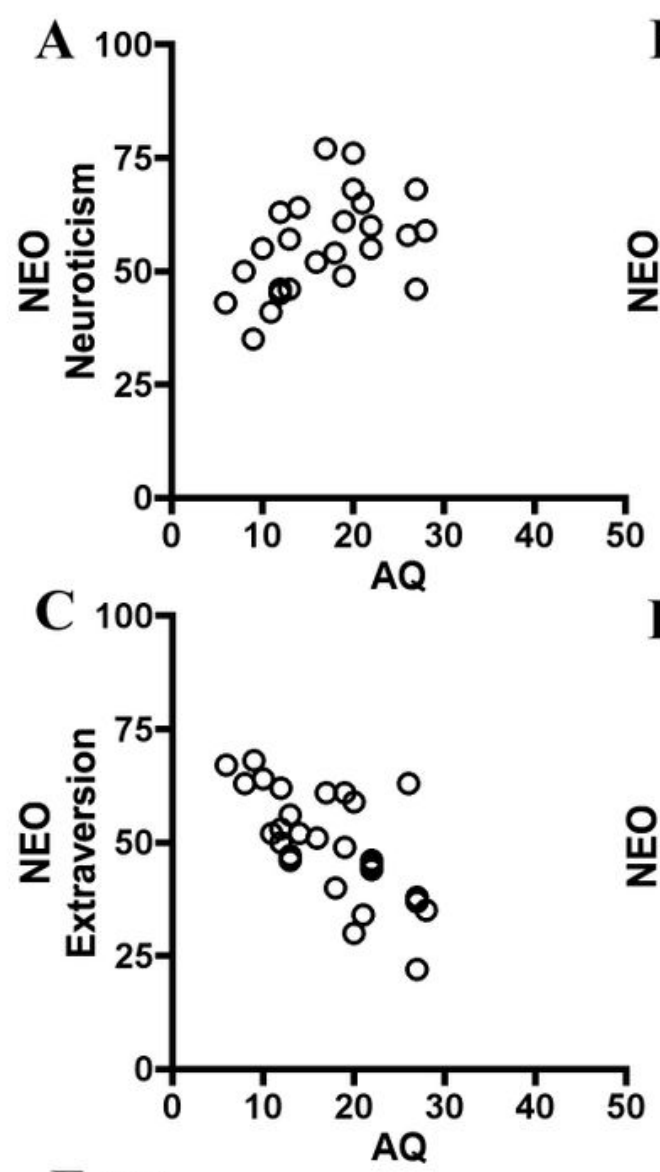

ASD
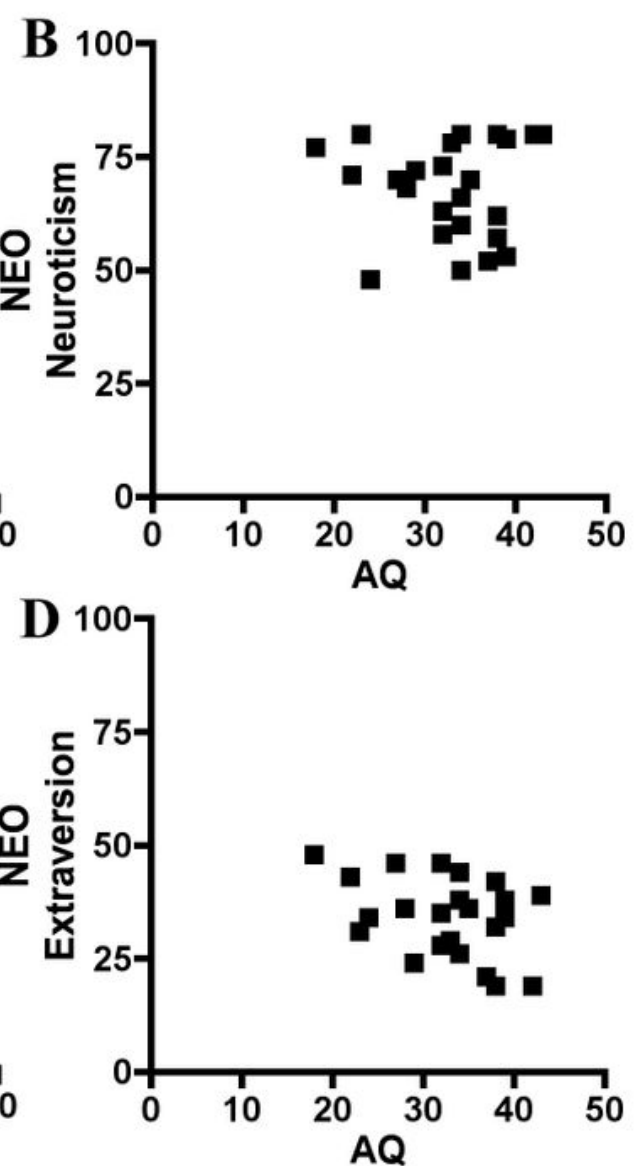
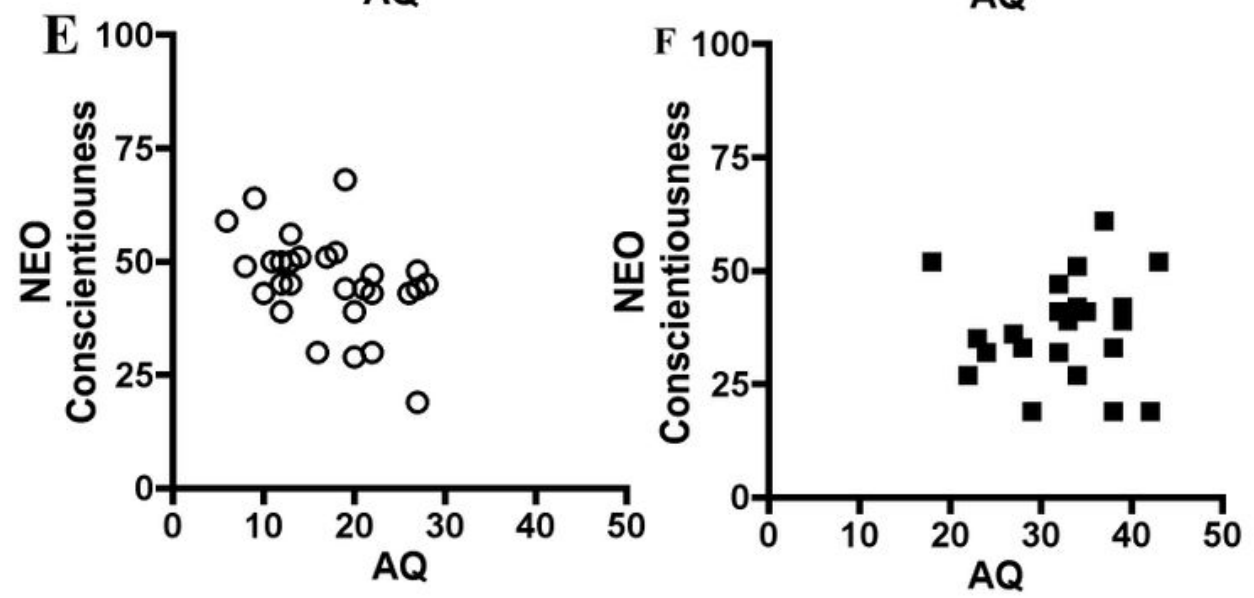

Figure 2

The correlation plots for the association between autistic traits and personality traits A, B: The correlations between autistic traits on the AQ and neuroticism on the NEO-PI-R in the control and ASD subjects. C, D: The correlations between autistic traits on the AQ and extraversion on the NEO-PI-R in the 
control and ASD subjects. E, F: The correlations between autistic traits on the AQ and conscientiousness on the NEO-PI-R in the control and ASD subjects. Data was shown in Table 5. 